\title{
Measurements of Light Atmospheric Hydrocarbons Over the Atlantic In Regions of Low Biological Activity
}

\author{
J. RudolPh AND F. J. JOHNEN
}

\author{
Institut für Atmosphärische Chemie, Kernforschungsanlage Jülich, Federal Republic of Germany
}

\begin{abstract}
More than 200 in situ measurements of several selected nonmethane hydrocarbons (NMHCs) were made in the remote marine atmosphere over the Atlantic between $40^{\circ} \mathrm{S}$ and $50^{\circ} \mathrm{N}$. Ethane, the by far longest lived of the NMHCs, showed southern hemispheric mixing ratios around $280 \mathrm{ppt}$, comparable in magnitude to most other previous measurements. The mixing ratios of ethene, propene, propane, and $i$ - and $n$-butane in the southern hemisphere were in the range of 10-30 ppt. For $i$-pentane and $n$-pentane the atmospheric mixing ratios in the southern hemisphere were below the detection limit of 15-20 ppt. These values are rather low compared to other published measurements in the marine atmosphere. This is due to the remoteness of the measuring locations and the very low biological activity in the surrounding ocean areas. For all alkanes the latitudinal profiles exhibit a considerable decrease from north to south. The relative hydrocarbon patterns show that the alkanes in the northern hemisphere are primarily due to long-range transport from continental or coastal areas. In general the transport times exceed several days. Consequently, the observed northern hemispheric ethene and propene mixing ratios must be, with few exceptions, primarily the result of oceanic emissions. The average difference of these compounds by a factor of 2 between the southern and the northern hemisphere can be explained by change of the phytoplankton concentration in ocean water. There is little or no indication for the existence of significant diurnal cycles for these two alkenes.
\end{abstract}

\section{INTRODUCTION}

In the past years, several investigations of light nonmethane hydrocarbons (NMHCs) in the remote marine atmosphere have been published [cf. Bonsang and Lambert, 1985; Bonsang et al., 1988; Ehhalt et al., 1985; Greenberg and Zimmermann, 1984; Rasmussen and Khalil, 1982; Rudolph and Ehhalt, 1981; Rudolph et al., 1982, 1984; Rudolph, 1988; Singh and Salas, 1982]. The results of these measurements indicate that several light NMHCs have substantial oceanic sources [cf. Rudolph and Ehhalt, 1981; Bonsang and Lambert, 1985; Bonsang et al., 1988; Singh and Salas, 1982]. This assumption is also supported by the presence of substantial amounts of light NMHCs in unpolluted ocean water [cf. Lamontagne et al., 1974; Bonsang et al., 1988]. However, most of these NMHC measurements were made in the vicinity of coastal areas or other biologically active regions of the oceans.

Since it is generally accepted that light NMHCs in ocean water are produced biologically, probably by phytoplankton, we can expect a considerable dependence of the atmospheric mixing ratios of short-lived NMHCs on the biological activity of the investigated regions of the ocean. In this paper we present the results of measurements of ethane, ethene, propane, propene, $i$-butane, $n$-butane, $i$-pentane, and $n$-pentane in the atmosphere over regions of the Atlantic with low primary production. The measurements were made during a cruise of the R/V Polarstern in March and April 1987 from Puerto Madryn (Argentina) to Bremerhaven (Germany).

\section{Experimental Procedure}

The hydrocarbon measurements were made by gas chromatography aboard the ship. The instrument was installed in a container on the observation deck. The air intake line

Copyright 1990 by the American Geophysical Union.

Paper number 89JD03253.

0148-0227/90/89JD-03253\$05.00 extended about $4 \mathrm{~m}$ beyond the reeling of the upper deck in order to minimize contamination from ship emissions. The stainless steel inlet line $(10 \mathrm{~mm}$ i.d., $\approx 10 \mathrm{~m}$ length) was permanently flushed with outside air at a flow rate of about $30 \mathrm{dm}^{3} \mathrm{~min}^{-1}$ to avoid wall losses and minimize possible contamination effects. The average residence time of the sample air in the inlet line was about $1 \mathrm{~s}$.

For each measurement, about 3-4 $\mathrm{dm}^{3}$ (STP) of air was passed through a preconcentration column ( $25 \mathrm{~cm}$ length, 4 $\mathrm{mm}$ i.d., packed with porous glass beads) immersed in liquid nitrogen. To avoid the condensation of oxygen, the pressure in the preconcentration loop was kept below $500 \mathrm{hPa}$. The trace gases were desorbed thereafter by removing the liquid nitrogen and heating the sample loop to $325 \mathrm{~K}$. The preconcentrated sample was injected onto the separation column (3 m, 2 mm i.d., packed with Porapack QS 100/120 mesh) by means of a multiport valve. The hydrocarbonis were measured with a flame ionization detector (FID). Details of the instrument are described by Rudolph et al. [1990].

The hydrocarbon mixing ratios were calculated by comparing the sample against reference air of known composition. Sample and reference air were measured by exactly the same procedure. The mixing ratios of the different hydrocarbons in the reference air were in the range of a few parts per billion to a fraction of a part per billion.

The reproducibility of the measurements was about $5 \%$, the lower limit of detection 5-20 ppt. The baseline noise of the FID was increased by the motion of the ship, probably due to the change of the flame positive relative to the collector electrode. Thus the lower limit of detection also depended on the swell of the sea.

No detectable blank values were observed during tests with "zero air." The time for one measurement, including preconcentration, was about 2.5 hours. The instrument allowed automatic, unattended operation for 24 hours or more. Except for short periods of instrument testing and maintenance, measurements were made for 24 hours a day, starting on March 21 (about $40^{\circ} \mathrm{S}$ ) and ending April $18\left(53^{\circ} \mathrm{N}\right)$. 
The cruise started on March 19, 1987, at Puerto Madryn in South Argentina $\left(43^{\circ} \mathrm{S}, 65^{\circ} \mathrm{W}\right)$ and ended on April 18, in Bremerhaven, West Germany $\left(53^{\circ} \mathrm{N}, 8^{\circ} \mathrm{E}\right)$. Between $30^{\circ} \mathrm{S}$ and $27^{\circ} \mathrm{N}$ the cruise track followed $30^{\circ}$ western longitude.

\section{RESULTS}

More than 200 measurements of light NMHCs were made during this cruise of the R/V Polarstern (ANT V/5). These in situ measurements covered a latitude range from $40^{\circ} \mathrm{S}$ to about $50^{\circ} \mathrm{N}$. Most of the samples were taken in a longitude belt between $20^{\circ} \mathrm{W}$ and $40^{\circ} \mathrm{W}$, about $50 \%$ of all measurements exactly along $30^{\circ} \mathrm{W}$ longitude. In general, two or more measurements were obtained within each degree of latitude. The measured mixing ratios of ethane, propane, $n$-butane, $n$-pentane, $i$-pentane, ethene, and propene are plotted in Figures $1 a-1 g$ as a function of latitude. All 217 measurements of ethane gave mixing ratios well above the detection limit; the reproducibility of the ethane measurements is better than $5 \%$. For propane the theoretical lower limit of detection was 5-10 ppt. However, for the given conditions, propane was not completely separated from methyl chloride. Thus small propane peaks corresponding to about $20 \mathrm{ppt}$ or less could not always be evaluated quantitatively, since very slight variations in the propane/methyl chloride separation or the baseline noise and drift already considerably changed the effective detection limit. It is therefore not possible to define a general lower limit of detection for propane. We estimate that it varied between 5 and 25 ppt. For about $80 \%$ of the 217 measurements, propane could be evaluated quantitatively. All propane measurements in the northern hemisphere were significantly above the detection limits.

For ethene, propene, and $n$-butane, more than $90 \%$ of the measurements gave results above the detection limits (5-10 ppt). However, mixing ratios were often very low, $20 \mathrm{ppt}$ or less. Accordingly, these low values have a considerable uncertainty, about 20-30\%.

For $i$-butane, about $30 \%$ of the measurements were below the detection limit of 5-10 ppt, mostly in the southern hemisphere. The uncertainty of the $i$-butane measurements for mixing ratios around $25 \mathrm{ppt}$ is estimated to be $20 \%$. For higher mixing ratios the reproducibility increases and is better than $10 \%$ above $100 \mathrm{ppt}$.

The detection limits for $i$ - and $n$-pentane are less favorable, about $15-20$ ppt. Only $25 \%$ of the values were quantifiable. All southern hemispheric mixing ratios of $i$ - and $n$-pentane were below 15-20 ppt. It should be noted that around $50^{\circ} \mathrm{N}$ the mixing ratios for all NMHC increased tremendously and reached values of several thousand ppt for all light NMHCs. These values around $50^{\circ} \mathrm{N}$ often exceed the mixing ratio scales in Figure 1 .

By far the largest part of the cruise was over remote ocean areas, in general more than $1000 \mathrm{~km}$ away from the nearest coastline. Two-day isentropic backward trajectories showed that between $35^{\circ} \mathrm{S}$ and $47^{\circ} \mathrm{N}$ the sampled air masses had no contact with continents for 48 hours or longer [Behr and Gravenhorst, this issue]. In addition, the oceanic areas investigated during this cruise and the surrounding regions were mostly "oceanic deserts" with very low biological productivity. [cf. Fleming, 1956]. This was confirmed by measurements of the chlorophyll concentration and the number of phytoplankton organisms in ocean water during this cruise [Kirst et al., 1989].
In Figure 2 the range of mixing ratios for the light hydrocarbon is shown, both for the northern and for the southern hemisphere together with other published data from the marine atmosphere. Measurements made within or near the Intertropical Convergence Zone (ITCZ) $\left(0^{\circ}-5^{\circ} \mathrm{N}\right)$ are not included in the averages. Also the data from latitudes north of $45^{\circ} \mathrm{N}$ were excluded, since the sampled air masses were subject to strong direct continental influence. For $i$ - and $n$-pentane we did not calculate average values because most of the measurements were below the limits of detection. Several of the $i$-butane measurements in the southern hemisphere were also below the detection limit; therefore the average in Figure 2, which is calculated from the measurements exceeding the detection limits, is probably slightly too high. To a lesser extent this might also be the case for the southern hemispheric $n$-butane and propane averages. The other averages are based on 70-90 measurements. It should be noted that the atmospheric mixing ratios of light NMHCs can exhibit systematic seasonal variations [Tille et al., 1985; Singh and Salas, 1982; Blake and Rowland, 1986; Rudolph et al., 1989].

\section{Discussion}

\section{The Distribution of Ethene and Propene}

Ethene and propene are emitted from the oceans in substantial amounts [cf. Rudolph and Ehhalt, 1981]. Since both compounds have short atmospheric lifetimes, we can expect that their atmospheric levels will be determined mainly by oceanic emissions. The production mechanism for light hydrocarbons in the surface waters of the oceans is still unknown, but several investigations [Wilson et al., 1970; Lamontagne et al., 1974; Swinnerton and Lamontagne, 1974] indicate that this process is closely linked with phytoplankton concentrations and thus with primary productivity.

The atmospheric levels of propene are quite low, on the average $9.8 \pm 5 \mathrm{ppt}$ in the southern hemisphere and $19.2 \pm$ $6 \mathrm{ppt}$ in the northern hemisphere. As can be seen from Figure 2, these values are significantly lower than other previously published measurements. Nearly all of the other measurements were made in coastal regions with high primary productivity. The oceanic regions covered by our measurements showed little biological activity. This can readily explain the observed differences. The average interhemispheric difference in our data of a factor of 2 is at first sight surprising. This value is based on more than 80 measurements in each hemisphere, and therefore the relative error of the mean north to south ratio is only $7 \%$, in spite of a significant scatter of the individual data points. This interhemispheric gradient might be explained by one of two factors, a faster removal rate in the southern hemisphere or stronger oceanic emissions in the northern hemisphere. A faster removal rate for propene in the southern hemisphere would require a higher $\mathrm{OH}$ radical concentration during the time of the cruise. There are theoretical speculations that $\mathrm{OH}$ might be higher in the southern hemisphere. However, there is one piece of evidence which indicates that during this ship cruise the oceanic hydrocarbon emissions might have been considerably larger in the northern hemisphere than in the southern hemisphere. Measurements of phytoplankton concentrations in ocean water during this cruise show that on the average the north/south ratio of the number 

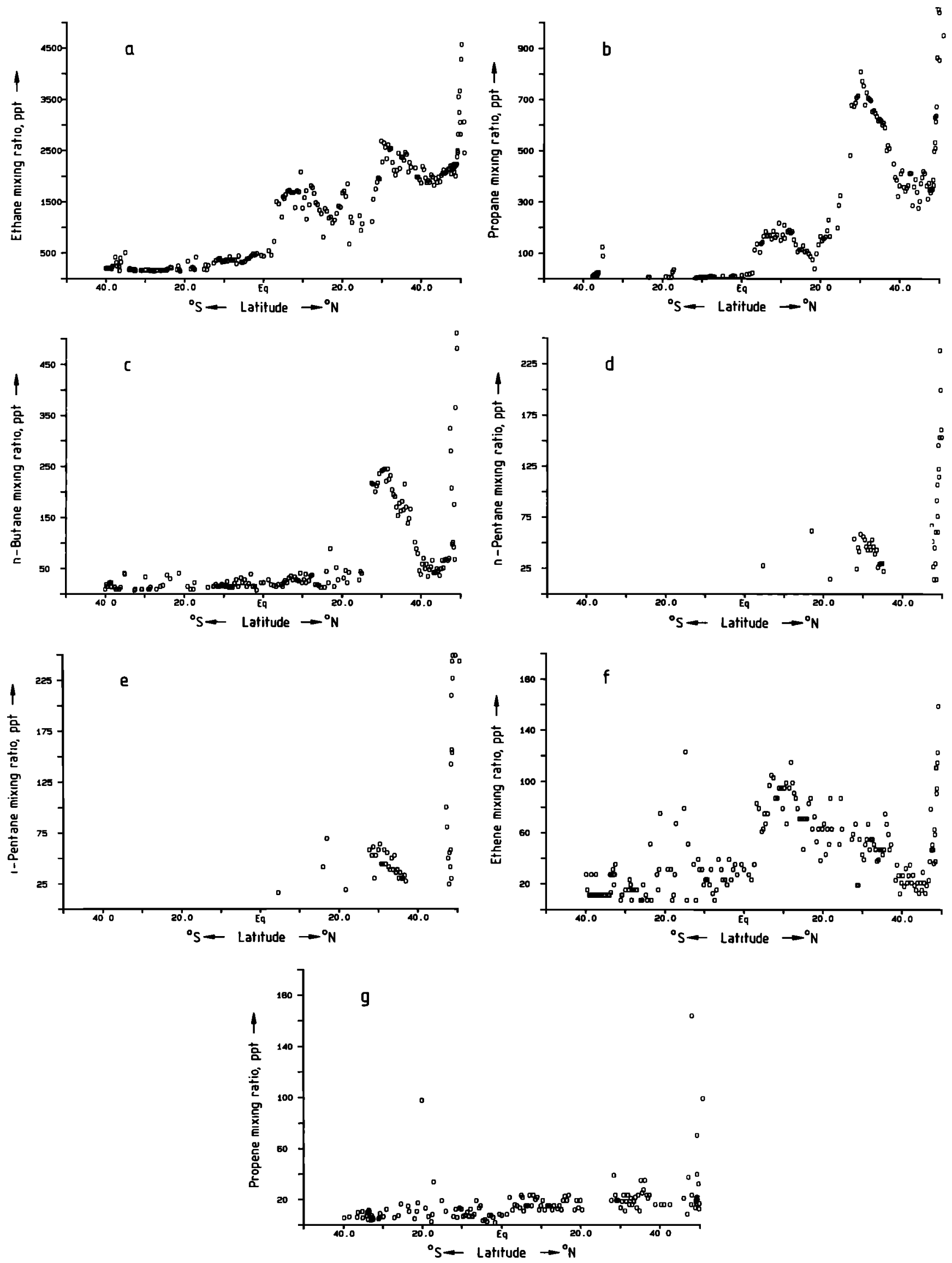

Fig. 1. Plot of hydrocarbon mixing ratios as function of latitude: $(a)$ ethane, $(b)$ propane, $(c) n$-butane, $(d) n$-pentane, $(e) i$-pentane, $(f)$ ethene, and $(g)$ propene. 

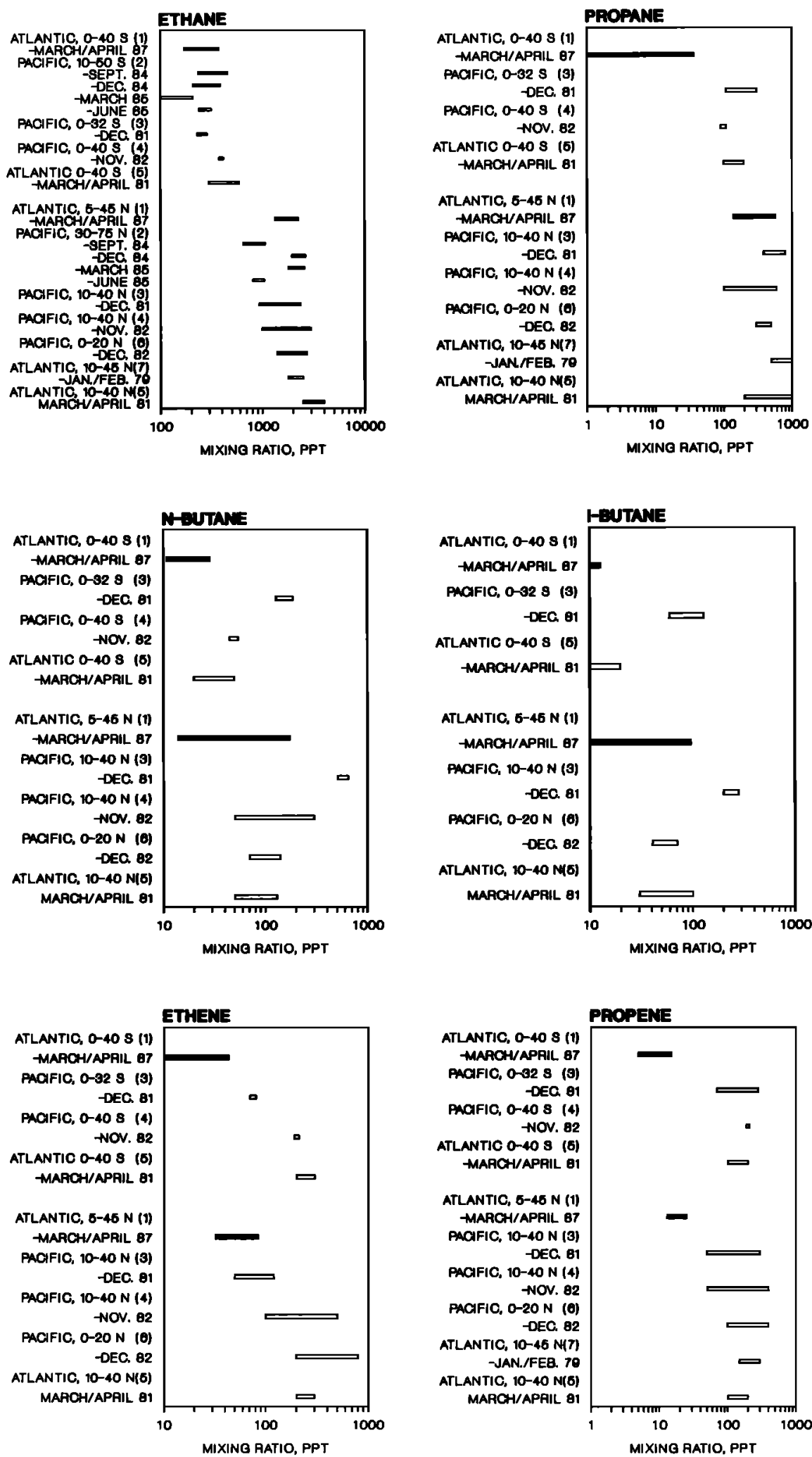

Fig. 2. Mixing ratios of some light NMHC in the marine atmosphere. The references are (1) this work, (2) Blake and Rowland [1986], (3) Singh and Salas [1982], (4) Bonsang and Lambert [1985], (5) Rudolph et al. [1982], (6) Greenberg and Zimmerman [1984], and (7) Rudolph and Ehhalt [1981].

of phytoplankton particles was 2.2 [Kirst et al., 1989]. If we assume that the oceanic emissions of alkenes are on the average roughly proportional to the oceanic phytoplankton concentration, this would readily explain the observed inter- hemispheric difference in the propene mixing ratios. There is not yet any established quantitative relationship between the concentration of phytoplankton and light NMHCs in ocean water. Thus these explanations of the distribution of alkenes 

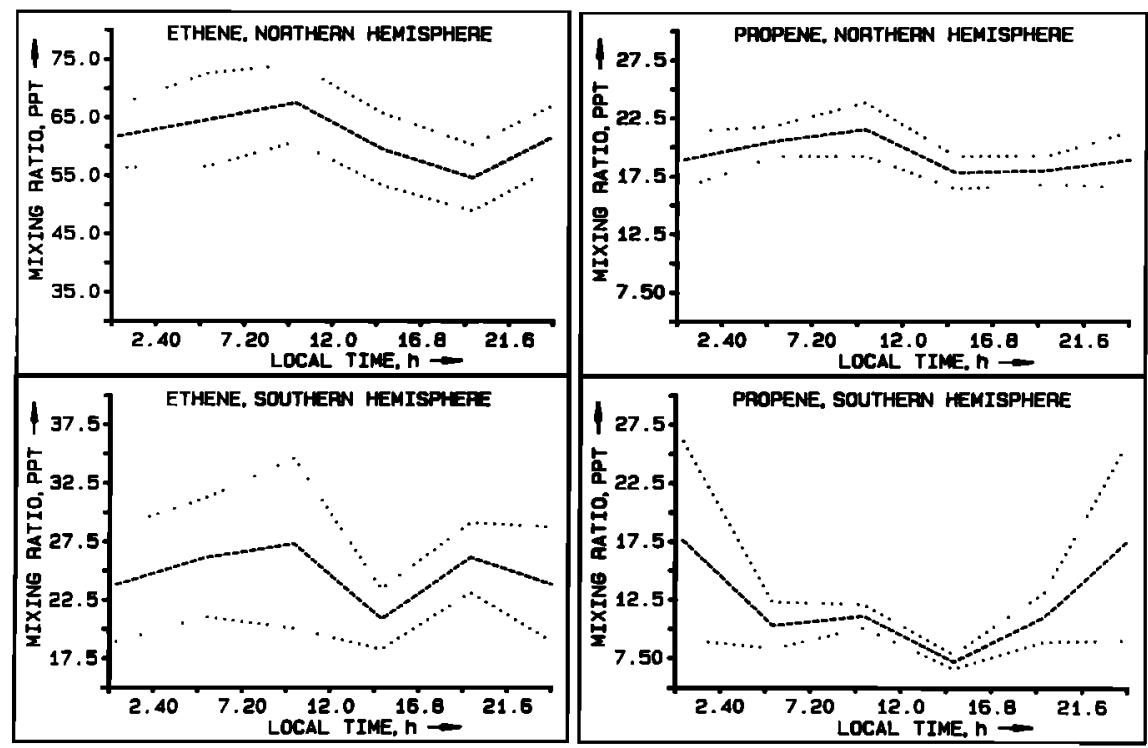

Fig. 3. Averaged diurnal cycles of ethene and propene in the northern and southern hemispheres.

in the marine atmosphere remain somewhat speculative. But, as mentioned before, there are several pieces of evidence pointing toward the existence of a direct or indirect correlation between oceanic phytoplankton and oceanic NMHCs. Ethene showed a very similar behavior, but the mixing ratios were higher on the average by a factor of 2.5-3. The average ratio of the ethene and propene abundances was 2.5 for the southern hemisphere and 2.9 for the northern hemisphere. There are a few estimates of oceanic emission rate for ethene and propene [Rudolph and Ehhalt, 1981; Ehhalt and Rudolph, 1984; Bonsang et al., 1988]. On a volume per volume basis the ratio of the ethene and propene emission rates is between 0.9 and 2.1. At low and midlatitudes the dominant loss mechanism is removal by $\mathrm{OH}$ radicals. It is 3 times faster for propene than for ethene $\left(k_{\mathrm{OH}}\right.$ at $298 \mathrm{~K} 2.5 * 10^{-11} \mathrm{~cm}^{3}$ molecule ${ }^{-1} \mathrm{~s}^{-1}$ for propene and 8.1 $* 10^{-12} \mathrm{~cm}^{3}$ molecule ${ }^{-1} \mathrm{~s}^{-1}$ for ethene [Atkinson, 1984]). For steady state conditions with the oceanic emissions balanced by photochemical removal we should therefore expect an ethene/propene ratio in the range of 2.7-6.3. Our experimentally observed ratios are at the lower end of this range but still somewhat higher than the relative emission rates. There was one significant exception in the latitude range between $5^{\circ} \mathrm{N}$ and $15^{\circ} \mathrm{N}$. In this latitude band the average ethene mixing ratio was $88 \mathrm{ppt}$, a factor of 5 above the propene mixing ratios and also significantly above the average ethene mixing ratio of $45 \mathrm{ppt}$ at higher latitudes $\left(15^{\circ} \mathrm{N}-45^{\circ} \mathrm{N}\right)$. This might be caused by a change in the oceanic ethene/propene emission ratio for this ocean area. However, both Lamontagne et al. [1974] and Bonsang et al. [1988] report rather constant ethene/propene ratios in ocean water for different ocean areas. Thus this explanation seems rather unlikely.

In the latitude range between $5^{\circ} \mathrm{N}$ and $15^{\circ} \mathrm{N}$ we also observed elevated mixing ratios for several longer-lived alkanes (cf. Figure 1). Furthermore, the visibility was considerably reduced due to increased concentrations of atmospheric aerosol particles. Measurements of trace metals indicative of mineral dust showed a significant peak in their atmospheric concentration (J. Völkening, private communication, 1989). All this clearly points toward continental influence on the sampled air masses. Although backward trajectories demonstrate that these air masses had no contact with continents for more than 2 days, they are compatible with the assumption that the air masses originated over tropical Africa. Measurements of light hydrocarbons over the west coast of Africa in June 1984 indicated that strong sources for ethene and propene exist in the coastal zone of West Africa [Rudolph, 1988]. Neither the transport times nor the original hydrocarbon composition are known with sufficient accuracy to justify quantitative estimates. Qualitatively, the time scales for transport and the average atmospheric residence times for ethene and propene are compatible with the idea that the elevated ethene mixing ratios were caused by long-range transport from the coastal regions of tropical West Africa. Thus advective transport requires more than 2 days, and propene with an average diurnal lifetime of 7 hours at low latitudes (a factor of more than 2 shorter than for ethene) would be depleted by a factor of at least several hundred. The remaining propene levels would be small compared to the observed average northern hemispheric propene mixing ratio of about $20 \mathrm{ppt}$.

\section{The Diurnal Cycle of Ethene and Propene}

Model calculations predict a systematic diurnal variation for ethene and propene [cf. Graedel, 1979]. Our data show a considerable nonsystematic variability. Therefore we divided each day into five equal periods and averaged the measurements from several days for each of the five time intervals. The averages are shown in Figure 3 as a function of local time. The data for the northern and southern hemisphere are plotted separately. The errors of the mean values are also shown. There is some indication that the alkene mixing ratios in the afternoon and early evening are slightly lower than those late at night or in the early morning. Except for the case of southern hemispheric propene where this difference is about a factor of 2 , this difference is $30 \%$ or less. Considering the uncertainties of these data, these changes are statistically insignificant. Model calculations based on a constant alkene flux from the oceans and a box model without vertical exchange [Graedel, 1979] predict 


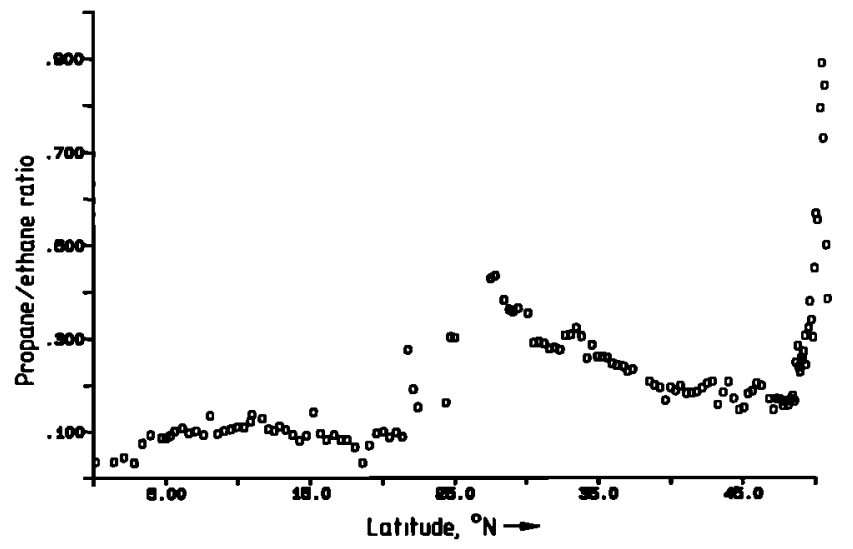

Fig. 4. Ratio of the propane and ethane concentrations as a function of latitude.

much more pronounced diurnal variations. Our experimental observations indicate that the factors determining the concentrations of alkenes in the marine boundary layer are more complex.

\section{The Distribution of Light Alkanes}

All alkanes show on the average a significant difference between the northern and the southern hemispheres with a pronounced increase around $50^{\circ} \mathrm{N}$ for the measurements made near the European continent. For ethane, the longest lived of the NMHCs, our measurements ( $278 \pm 104$ ppt for $0^{\circ}-40^{\circ} \mathrm{S}$ and $1810 \pm 460 \mathrm{ppt}$ for $5^{\circ} \mathrm{N}-45^{\circ} \mathrm{N}$ ) are very similar to other published data (Figure 2). Also our northern hemispheric propane values $(360 \pm 220 \mathrm{ppt})$ fall well within the range of other measurements. However, our results for the other NMHCs and southern hemispheric propane are at the lower end of the range of these data, often even significantly lower (Figure 2). This indicates that our measurements from the ANT V/5 cruise were probably substantially less influenced by continental or marine hydrocarbon emissions than most of the other measurements. Still, the existence of significant structures in our latitudinal alkane profiles (Figure 1) which are not visible for propene demonstrates that long-range transport has considerable impact on the hydrocarbon composition even for the atmosphere over the middle of the Atlantic, especially in the northern hemisphere.

Three latitudinal bands near $10^{\circ} \mathrm{N}, 30^{\circ} \mathrm{N}$, and $50^{\circ} \mathrm{N}$ show increased mixing ratios of ethane, propane, $n$-butane, and $i$-butane. However, the extent of these increases differs considerably. This is demonstrated in Figure 4 . Here the ratios of the propane and ethane concentrations in the northern hemisphere are plotted as a function of latitude. There is a systematic trend. Changes in the mixing ratios of alkanes with shorter atmospheric lifetimes are more pronounced than changes of longer-lived alkanes. This is clearly visible from the correlation plot in Figure 5. Since the data cover a range of several orders of magnitude, they are shown in a log-log scale. The relative decrease in propane is larger than for ethane, whereas the mixing ratios of $i$-butane and $n$-butane whose atmospheric lifetimes are very similar [cf. Rudolph and Ehhalt, 1981] show a very good linear dependence with a slope of one in the log-log plot (Figure $5 b$ ).
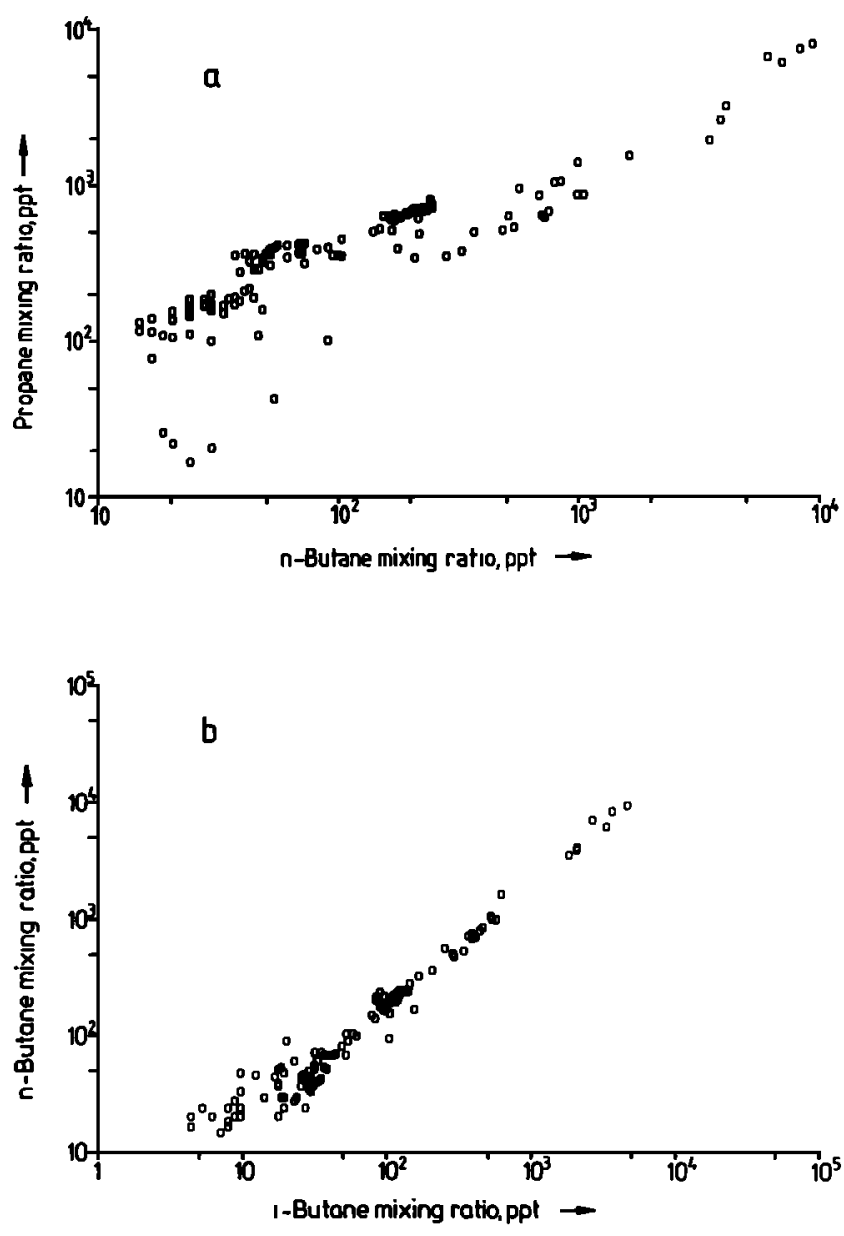

Fig. 5. Correlation between the northern hemispheric mixing ratios of different alkanes (logarithmic scales): (a) Propane versus $n$-butane and (b) $n$-butane versus $i$-butane.

\section{Long-Range Transport of Alkanes}

The change in the concentration ratio $r_{i j} \equiv C_{i} / C_{\mathrm{j}}$ of two hydrocarbons $i$ and $j$ due to photochemical removal as a function of time in a given air mass can be described as follows:

$$
r_{i j}=r_{i j}^{0} \exp \left(t\left(1 / \tau_{j}-1 / \tau_{i}\right)\right)
$$

with

$$
r_{i j}^{0}=r_{i j} \text { at } t=0
$$

$\tau_{t}$ and $\tau_{j}$ are the lifetimes of compounds $i$ and $j$, respectively. Since the only known relevant removal mechanism for light alkanes in the troposphere is the reaction with $\mathrm{OH}$ radicals, $\tau$ can be calculated from the $\mathrm{OH}$ radical concentration and the reaction rate constant $k_{\mathrm{OH}}$ :

$$
\tau_{i}=1 /\left({ }_{i} k_{\mathrm{OH}} \cdot[\mathrm{OH}]\right)
$$

Equation (1) can then be written as

$$
r_{i j}=r_{i j}^{0} \exp \left(t \cdot[\mathrm{OH}] \cdot\left({ }_{j} k_{\mathrm{OH}}-k_{\mathrm{OH}}\right)\right)
$$

We can use a second equation describing the concentration ratio of another pair of hydrocarbons $r_{k j}=C_{k} / C_{J}$ to eliminate $t \cdot[\mathrm{OH}]$ from equation (3) and obtain the following equation describing the dependence of $r_{i j}$ from $r_{k j}$ : 


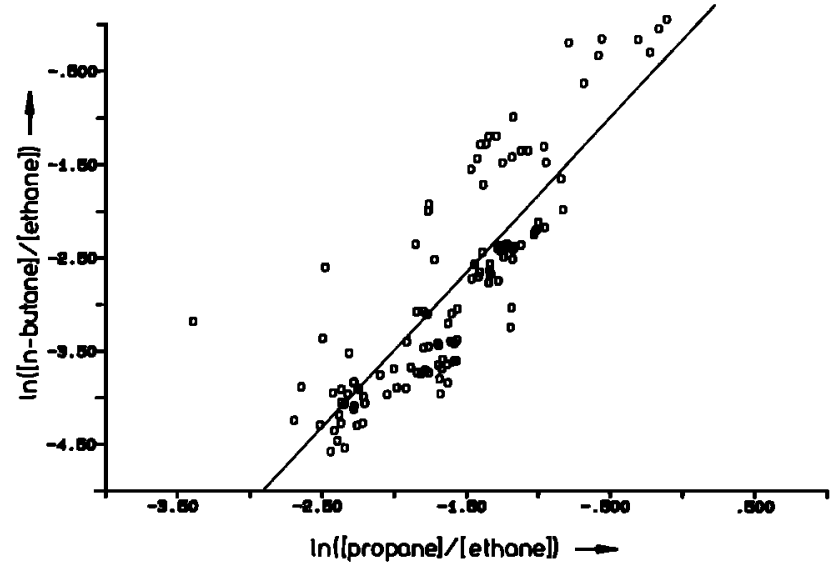

Fig. 6. Plot of the logarithm of the $n$-butane/ethane concentration ratio versus the logarithm of the propane/ethane ratio. The solid line is a least squares fit of the data points.

$$
\begin{aligned}
\ln r_{i j}= & \left({ }_{j} k_{\mathrm{OH}}-{ }_{i} k_{\mathrm{OH}}\right) /\left({ }_{j} k_{\mathrm{OH}}-{ }_{k} k_{\mathrm{OH}}\right) \cdot \ln r_{k j}+\ln r_{i j}^{0} \\
& -\ln r_{k j}^{0} \cdot\left({ }_{j} k_{\mathrm{OH}}-k_{\mathrm{OH}}\right) /\left({ }_{j} k_{\mathrm{OH}}\right) /\left({ }_{j} k_{\mathrm{OH}}-{ }_{k} k_{\mathrm{OH}}\right)
\end{aligned}
$$

A plot of $\ln r_{i j}$ versus $\ln r_{k j}$ should give a straight line with the slope of

$$
a=\left({ }_{\jmath} k_{\mathrm{OH}}-{ }_{i} k_{\mathrm{OH}}\right) /\left({ }_{\jmath} k_{\mathrm{OH}}-{ }_{k} k_{\mathrm{OH}}\right)
$$

and the intercept,

$$
b=\ln r_{i j}^{0}-a \cdot \ln r_{k j}^{0}
$$

In order to apply equation (4) to our data we have to assume that local sources of alkanes, that is, oceanic emissions, do not contribute significantly to the observed alkane concentrations. Bonsang et al. [1988] published measurements of light NMHCs both in the atmosphere and in ocean water for a region of the Indian Ocean where the atmospheric hydrocarbon concentrations were dominated by the oceanic emissions. They report that the oceanic emissions of both ethene and propene always exceeded the fluxes of alkanes by a factor of roughly 5-10. The corresponding atmospheric mixing ratios of propene are larger than the alkane mixing ratios by a factor of 2 or more. If we assume a similar pattern of the oceanic NMHC emissions for the Atlantic, we can estimate the oceanic contribution to the atmospheric alkanes from the measured propene mixing ratios. From our average southern hemispheric propene mixing ratio of $10 \pm 5 \mathrm{ppt}$ we estimate an upper limit of about 5-7 ppt. This is a considerable fraction of the observed southern hemispheric alkane mixing ratios (except for ethane), and we therefore cannot apply equation (4) to these data. For the northern hemisphere the situation is more favorable. From the average propene concentration of $19 \pm$ $6 \mathrm{ppt}$ we estimate an upper limit of about $10 \mathrm{ppt}$ for the contribution of local or regional oceanic emissions to the atmospheric alkane mixing ratios. This is only $20 \%$ of the average $i$-butane mixing ratios, $10 \%$ for $n$-butane, and less than $3 \%$ for propane and ethane. This generally justifies our assumption for the measurements made north of the ITCZ.

In Figure 6 we show the propane/ethane versus the $n$-butane/ethane concentrations in a log-lot plot. A least squares fit gives a regression coefficient of 0.84 . The slope is
$1.66 \pm 0.1$, and the intercept is $0.15 \pm 0.17$. We can calculate the theoretical slope from equation (5) and published reaction rate constants [cf. Hampson and Garvin, 1978; Atkinson, 1984]. The theoretical value of 1.86 differs by only $11 \%$ from the slope of the fit to the experimental data. Considering the rather generalizing assumptions we made to derive equation (4), this difference is surprisingly small, although slightly larger than the relative statistical error of $6 \%$. This gives some confidence that on the average the observed changes in the hydrocarbon concentration ratios as a first approximation can be described by equations (3) and (4).

In principle we can use equation (3) to estimate the average age of the air masses; however, we do not know the initial concentration ratio $r_{i j}^{0}$, that is, the average emission ratios of compounds $i$ and $j$. Furthermore, both the actual $\mathrm{OH}$ radical concentrations and their variations with latitude are not known. The latter difficulty can be avoided if we calculate the ratio of $t / \tau$, i.e., express the time as multiples of the atmospheric lifetime of a certain alkane, e.g., $n$-butane.

The emission ratios $r_{i j}^{0}$ cannot be calculated from the intercept of equation (4), since equation (6) only defines a relationship between $r_{i j}^{0}$ and $r_{k j}^{0}$ :

$$
r_{i j}^{0}=\exp (b) r_{k j}^{0} \wedge a
$$

But from this relationship, published global data for continental NMHC emissions [cf. Ehhalt and Rudolph, 1984], and our measurements of alkanes in continental air masses around $50^{\circ} \mathrm{N}$ we can estimate $r^{0}$ for different pairs of alkanes and compare the results obtained for $t / \tau$. This is done in Figure 7. The relative time scales $t / \tau$ are all scaled to the lifetime of $\boldsymbol{n}$-butane to allow a direct comparison.

$$
t / \tau_{n \text {-butane }}=\ln \left[r_{i j} / r_{i j}^{0}\right] \cdot{ }_{n \text {-butane }} k_{\mathrm{OH}} /\left[{ }_{j} k_{\mathrm{OH}}-{ }_{i} k_{\mathrm{OH}}\right]
$$

The estimated emission ratios $r^{0}$ are 0.9 for propane/ethane, 0.7 for $n$-butane/ethane, and 0.4 for $i$-butane/ethane. In Figure 7 we also show the change in $t / \tau_{n \text {-butane }}$ which would be caused by a change of $\pm 30 \%$ in the emission ratios $r_{i j}$. As can be seen from a comparison of the values derived from the three different alkane ratios, the results agree reasonably well.

The largest differences were observed between $15^{\circ} \mathrm{N}$ and $25^{\circ} \mathrm{N}$. In this region the lowest mixing ratios for $i$-butane and $n$-butane north of the ITCZ were found, and they were comparable in magnitude to the southern hemispheric values. From our estimates we can calculate that local oceanic emissions may contribute up to $30-50 \%$ to the $n$-butane and $i$-butane mixing ratios of $20-50 \mathrm{ppt}$ and roughly $15 \mathrm{ppt}$, respectively. Consequently, the transport times calculated from equation (8) are about $0.5-1 \tau_{n \text {-butane }}$ to short. For other latitudes and the transport times calculated from the propane/ethane ratios the possible effect of local oceanic emissions is much smaller.

The estimated times (Figure 6) range from $3-4 \tau_{n \text {-butane }}$ at tropical latitudes and between $40^{\circ}$ and $45^{\circ} \mathrm{N}$ to $1.5-2 \tau_{n \text {-butane }}$ around $30^{\circ} \mathrm{N}$. North of $47^{\circ} \mathrm{N}$, low values, often close to zero, are found.

The atmospheric lifetime of $\boldsymbol{n}$-butane at tropical latitudes averages about 2 days [Rudolph and Ehhalt, 1981]. As a result of the decrease of the $\mathrm{OH}$ radical concentrations with increasing latitude, the $n$-butane lifetime is longer at higher latitudes. On the global average the $\tau_{n \text {-butane }}$ is 7 days [Rudolph and Ehhalt, 1981]. If we assume that the main 

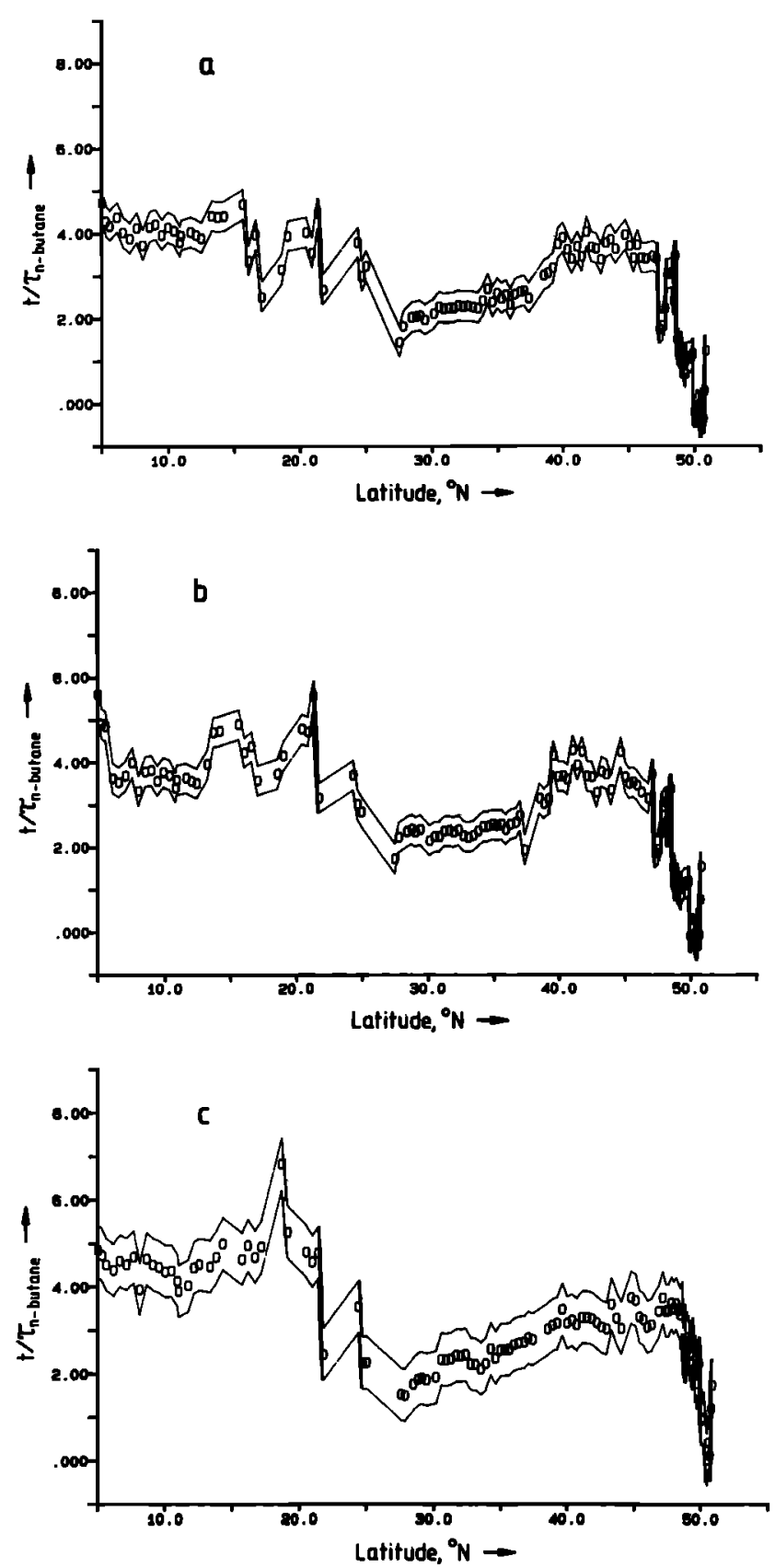

Fig. 7. Average age of the samples air masses relative to the atmospheric $n$-butane lifetime (a) calculated from the propane/ ethane concentration ratio, (b) calculated from the $n$-butane/ethane concentration ratio, and $(c)$ calculated from the $i$-butane/ethane concentration ratio. The solid lines indicate the range of uncertainty caused by an error of $\pm 30 \%$ for the initial concentration ratios.

regions of alkane emissions into the atmosphere are located over the continents or in the coastal areas of the oceans, we can estimate that south of $47^{\circ} \mathrm{N}$ all sampled air masses had no contact with continents for at least several days. This is supported by the calculated 2-day backward trajectories [Behr and Gravenhorst, this' issue].

Our estimates are based on a simplified picture and neglect the fact that in a real atmosphere the hydrocarbon composition is determined by the mixing of air masses of different origin and age. Since the hydrocarbon concentration ratios in an air parcel change exponentially with time (cf. equation
(1)) we obtain a nonlinear average which is difficult to interpret. Furthermore, at low hydrocarbon mixing ratios the impact of even very small local sources (e.g., oceanic emissions) can cause a considerable bias. For this reason we caninot use our southern hemispheric NMHC measurements or any of the alkene data to estimate the age of the air masses. Nevertheless, the estimates based on the northern hemispheric alkane measurements give consistent results and demonstrate that photochemical removal processes are clearly visible in the change of the hydrocarbon pattern observed over remote ocean areas.

\section{Conclusions}

The cruise of the R/V Polarstern in spring 1987 (ANT V/5) covered predominantly ocean areas of low biological productivity. Furthermore, the sampled air masses had, with very few exceptions, no contact with continents for more than 2 days. For the northern hemisphere this is supported by the observed systematic changes in the pattern of the measured light alkanes. As a consequence the observed NMHC mixing ratios are at the lower end of the range of published NMHC measurements in the maritime atmosphere. In particular, the atmospheric mixing ratios of ethene and propene are lower than all previously published marine data. The average north/south difference for ethene and propene of a factor of 2 corresponds to the difference in the average oceanic phytoplankton levels. This observatior. and the remoteness of the investigated oceanic areas strongly support the assumption that the observed atmospheric alkene levels are due to oceanic emissions.

The change in the pattern of the saturated hydrocarbons north of the ITCZ is compatible with the idea of predominantly continental or coastal sources and photochemical removal of the different alkanes at rates proportional to their rate constants for the reaction with $\mathrm{OH}$ radicals. The presented estimates of the age of the air masses can only be considered as a simplified first approximation. However, the results are consistent, and further investigations in combination with more detailed trajectory studies as well as measurements of air mass composition over the potential source regions might give more insight into both atmospheric long-range transport and photochemical removal processes.

Acknowledgments. We thank the Alfred-Wegener-Institut für Polarforschung in Bremerhaven for logistical support and the opportunity to participate in this cruise the R/V Polarstern. We would also like to thank the other scientists who participated in this cruise and the crew of the Polarstern for their valuable help and the excellent working conditions during this cruise. This work was supported financially by the Bundesminister für Forschung und Technologie of the Federal Republic of Germany through grant 07441025 .

\section{REFERENCES}

Atkinson, R., Evaluation of kinetic and mechanistic data for modeling of photochemical smog, J. Phys. Chem. Ref. Data, 13, 315-344, 1984

Behr, H.-D., and G. Gravenhorst, Synoptic situation in the Atlantic Ocean region during ANT V/5, J. Geophys. Res., this issue.

Blake, D. R., and F. S. Rowland, Global atmospheric concentrations and source strength of ethane, Nature, 321, 231-233, 1986.

Bonsang, B., and G. Lambert, Nonmethane hydrocarbons in an oceanic atmosphere, J. Atmos. Chem., 2, 257-271, 1985.

Bonsang, B., M. Kanakidou, G. Lambert, and P. Monfray, The 
marine source of $\mathrm{C}_{2}-\mathrm{C}_{6}$ aliphatic hydrocarbons, J. Atmos. Chem., $6,3-20,1988$.

Bürgermeister, S., R. L. Zimmermann, H. W. Georgii, H. G. Bingemer, G. O. Kirst, M. Janssen, and W. Emst, On the biogenic origin of dimethylsulfide: Relation between chlorophyll, ATP, organismic DMSP, phytoplankton species, and DMS distribution in Atlantic surface water and atmosphere, J. Geophys. Res., this issue.

Ehhalt, D. H., and J. Rudolph, On the importance of light hydrocarbons in multiphase atmospheric systems, Ber. Kernforschungsanlage Jülich, Rep. JÜL-1942, pp. 1-43, Inst. für Atmos. Chemie, Jülich, Federal Republic of Germany, 1984.

Ehhalt, D. H., J. Rudolph, F. X. Meixner, and U. Schmidt, Measurements of selected $\mathrm{C}_{2}-\mathrm{C}_{5}$ hydrocarbons in the background troposphere: Vertical and latitudinal variations, J. Atmos. Chem., $3,29-52,1985$.

Fleming, R. H., The influence of hydrographic conditions on the behavior of fish, FAO Fish. Bull., 9, 181-196, 1956.

Graedel, T. E., The kinetic photochemistry of the marine atmosphere, J. Geophys. Res., 84, 273-286, 1979.

Greenberg, J. P., and P. R. Zimmermann, Nonmethane hydrocarbons in remote tropical, continental, and marine atmospheres, $J$. Geophys. Res., 89, 4767-4778, 1984.

Hampson, R. F., and D. Garvin (Eds.), Reaction rate and photochemical data for atmospheric chemistry 1977, Spec. Publ. 513, Natl. Bur. of Stand., Washington, D. C., 1978.

Lamontagne, R. A., J. W. Swinnerton, and V. J. Linnenbom, $\mathrm{C}_{1}-\mathrm{C}_{4}$ hydrocarbons in the North and South Pacific, Tellus, 26, 71-77, 1974.

Rasmussen, R. A., and M. A. K. Khalil, Latitudinal distributions of trace gases in and above the boundary layer, Chemosphere, 11 , 227-235, 1982.

Rudolph, J., Two-dimensional distribution of light hydrocarbons: Results from the STRATOZ III experiment, J. Geophys. Res., 93, 8367-8377, 1988.

Rudolph, J., and D. H. Ehhalt, Measurements of $\mathrm{C}_{2}-\mathrm{C}_{5}$ hydrocarbons over the North Atlantic, J. Geophys. Res., 86, 11.959$11.964,1981$.

Rudolph, J., D. H. Ehhalt, A. Khedim, and C. Jebsen, Latitudinal profiles of some $C_{2}-C_{5}$ hydrocarbons in the clean troposphere over the Atlantic, paper presented at 2nd Symposium on Composition of the Nonurban Troposphere, Am. Meteorol. Soc., Boston, Mass., 1982.

Rudolph, J., C. Jebsen, A. Khedim, and F. J. Johnen, Measurements of the latitudinal distribution of light hydrocarbons and halocarbons over the Atlantic, in Proceedings of the 3rd European Symposium on Physico-Chemical Behaviour of Atmospheric Pollutants, edited by B. Versino and G. Angeletti, pp. 492-501, D. Reidel, Hingham, Mass., 1984.

Rudolph, J., A. Khedim, and D. Wagenbach, The seasonal variation of light norimethane hydrocarbons in the Antarctic troposphere, J. Geophys. Res., 94, 13,039-13,044, 1989.

Rudolph, J., F. J. Johnen, A. Khedim, and G. Pilwat, The use of automated on line gaschromatography for the monitoring of organic trace gases in the atmosphere at low levels, Int. J. Environ. Anal. Chem., 38, 143-145, 1990.

Singh, H. B., and L. J. Salas, Measurement of selected light hydrocarbons over the Pacific Ocean: Latitudinal and seasonal variations, Geophys, Res. Lett., 9, 842-845, 1982.

Swinnerton, J. W., and R. A. Lamontagne, Oceanic distribution of low-molecular-weight hydrocarbons, Environ. Sci. Technol., 8, 657-663, 1974.

Tille, K. J. W., M. Sarelsberg, and K. Bächmann, Airborne measurements of nonmethane hydrocarbons over western Europe: Vertical distribution, seasonal cycles of mixing ratios and source strength, Atmos. Environ., 11, 1751-1760, 1985.

Wilson, D. W., J. W. Swinnerton, and R. A. Lamontagne, Production of carbon monoxide and gaseous hydrocarbons in seawater: Relationship to dissolved organic carbon, Science, 168, 1577$1579,1970$.

F. J. Johnen and J. Rudolph, Institut für Atmosphärische Chemie, Kernforschungsanlage Jülich GmbH, Postfach 1913, Jülich, Federal Republic of Germany.
(Received January 31, 1989; revised July 18, 1989; accepted October 19, 1989.) 